\title{
Hip fracture incidence in Japan: Estimates of new patients in 2012 and 25-year trends
}

\author{
H. Orimo ${ }^{1}$ - Y. Yaegashi ${ }^{2}$ - T. Hosoi ${ }^{1}$ - Y. Fukushima ${ }^{3}$ - T. Onoda ${ }^{2}$. \\ T. Hashimoto ${ }^{4}$ K. Sakata ${ }^{2}$
}

Received: 3 July 2015 / Accepted: 15 December 2015 / Published online: 5 January 2016

(C) International Osteoporosis Foundation and National Osteoporosis Foundation 2015

\begin{abstract}
Summary We estimated the number of hip fracture patients in 2012 in Japan and investigated the trends in incidence during a 25-year period from 1987 to 2012. Despite the increasing number of patients, the incidence of hip fracture in both men and women aged 70-79 years showed the possibility of decline.

Introduction The objectives of this study were to estimate the number of hip fracture patients in 2012, to investigate the trends in incidence during a 25-year period from 1987 to 2012, and to determine the regional differences in Japan.

Methods Data were collected through a nationwide survey based on hospitals by a mail-in survey. Hip fracture incidences by sex and age and standardized incidence ratios by region were calculated.

Results The estimated numbers of new hip fracture patients in 2012 were 175,700 in total (95\% CI 170,300 $181,100), 37,600(36,600-38,600)$ for men and 138,100 $(134,300-141,900)$ for women. The incidence rates in both men and women aged 70-79 years were the lowest in the 20-year period from 1992 to 2012 . The incidence
\end{abstract}

Y. Yaegashi

yumiyae@iwate-med.ac.jp

1 Kenkoin Clinic, Chuo-ku, Tokyo, Japan

2 Department of Hygiene and Preventive Medicine, School of Medicine, Iwate Medical University, 2-1-1 Nishitokuta, Yahaba-cho, Shiwa-gun, Iwate 028-3694, Japan

3 Ministry of Health, Labour and Welfare, Chiyoda-ku, Tokyo, Japan

4 Department of Public Health, Wakayama Medical University, Wakayama, Japan was higher in western areas of Japan than that in eastern areas in both men and women; however, the difference in the incidence of hip fracture between western and eastern areas is becoming smaller.

Conclusions Despite the increasing number of new patients, the incidence of hip fracture in both men and women aged 70 79 years showed the possibility of decline. The exact reasons for this are unknown, but various drugs for improving bone mineral density or preventing hip fracture might have influenced the results. A decrease in the differences in nutrient intake levels might explain some of the change in regional differences in Japan.

Keywords Aging · Drug therapy $\cdot$ Hip fracture $\cdot$ Incidence Osteoporosis · Time trends

\section{Introduction}

Osteoporosis is a common disease characterized by a systemic impairment of bone mass and microarchitecture that results in fragility fractures [1]. Osteoporotic fractures are a frequent and important cause of disability and high medical costs worldwide [2]. Hip fracture is the most serious outcome of osteoporosis. In addition to the substantial cost burden, hip fractures are also associated with a high mortality rate [3].

The Comprehensive Survey of Living Conditions showed that fractures and falls accounted for $10 \%$ ( $7.0 \%$ for men and $11.7 \%$ for women) of the needs for long-term care [4]. The number of people in Japan who need some support in daily life or who need in long-term care need is about 5.5 million, an increase of about 1.5 times over the past decade, and the number has been increasing steadily [5]. Hence, a variety of countermeasures against hip fracture and 
osteoporosis are urgent medical and social issues in the rapidly aging Japanese population.

A nationwide survey in Japan has been implemented every 5 years since 1987, and the trend in hip fracture incidence has been reported. The first nationwide survey was carried out in 1987 to clarify the sex-specific and agespecific incidences of hip fractures, and the estimated number of new patients in 1987 was about 53,200 [6]. The second nationwide survey, using a different method to improve accuracy, was performed in 1992 and the number of new patients was estimated to be 76,600 [7]. In the third nationwide survey, carried out in 1997, the estimated number of new patients was 92,400 [8]. In the fourth survey in 2002 , the estimated number was 117,900 [9]. In the fifth survey in 2007 , the estimated number of new patients was 148,100 . The number of new patients with hip fracture increased 2.8-fold in the 20-period from 1987 to 2007 [10].

The objectives of this study were to estimate the number of patients with hip fracture in 2012, to investigate the trends in incidence during the 25-year period from 1987 to 2012, and to determine the regional distributions of hip fracture incidence in Japan.

\section{Subjects and methods}

\section{Sampling method}

\section{For a nationwide estimate}

To estimate the number of new hip fracture patients nationwide in the sixth survey in 2012, hospitals and clinics including or specializing in orthopedics throughout Japan were divided into 13 strata according to the number of beds, maintaining comparability with previous surveys. In Japan, small hospitals with 19 or fewer beds are defined as clinics. All hospitals with 200 beds or more were included and hospitals with 199 or fewer beds were randomly selected by Neyman's allocation method [11] to minimize standard error. In this survey, among 7201 orthopedic institutions in Japan, 4165 institutions were selected as sites to investigate a nationwide estimate, using the same sample size as that in previous surveys (Table 1). The number of new patients with hip fracture was estimated by the following formula:

Number of patients $=\sum \frac{N_{i}}{n_{i}} \cdot P_{i}$,

where $N_{i}$ is the number of surveyed institutions in each stratum, $n_{i}$ is the number of responding institutions in each stratum, and $P_{i}$ is the summation of the number of new patients in each stratum [8].

\section{For regional estimates}

Data from 5210 institutions, all hospitals with 20 beds or more and 282 clinics, were used for regional estimates to improve estimation accuracy. Data from clinics that had been randomly selected for the nationwide estimate were used (Table 1).

We calculated regional estimates of hip fracture incidence dividing the nation to 12 regions from east to west, such as, Hokkaido, Tohoku, Kanto I, Kanto II, Hokuriku, Tokai, Kinki I, Kinki II, Chugoku, Shikoku, Kitakyushu, and Minamikyushu, which was based on the National Health and Nutrition Survey in Japan.

The standardized incidence ratio was calculated as follows:

Standardized incidence ratio $=\frac{B}{\sum(I \times P)}$,

where $B$ is the estimated number of patients in each region, $I$ is the nationwide incidence of hip fracture by sex and age groups, and $P$ is the regional population by sex and age groups.

Incidences by sex and age groups were calculated on the basis of the estimated number of new patients. This incidence was multiplied by the population by the sex and age groups in each region to obtain the expected number of patients. The ratio of estimated number of patients to expected number was calculated as the standardized incidence ratio.

Population figures from the 2010 national census were used to calculate the incidence of hip fracture and the standardized incidence ratio by region.

\section{Questionnaire}

A questionnaire was sent by mail to all participating or selected hospitals and clinics based on hospital data from Wellness Co., Ltd. We asked for information on the number of new patients with hip fracture between January 1 and December 31 in 2012 and information on each patient's sex and age. Patients that underwent surgery for hip fracture at other institutions or patients for rehabilitation were excluded to avoid double counting of new hip fracture patients.

\section{Results}

\section{Response rates}

For a nationwide estimate, replies were obtained from 2615 institutions, a response rate of $62.8 \%$. The response rate was highest $(71.3 \%)$ in clinics with less than 19 beds and was lowest $(56.2 \%)$ in hospitals with $20-49$ beds. For regional estimates, replies were obtained from 3170 institutions, a 
Table 1 Number of institutions and sampling numbers for a nationwide estimate and regional estimates by stratum

\begin{tabular}{lllll}
\hline Stratum no. & No. of beds & $\begin{array}{l}\text { No. of } \\
\text { institutions }\end{array}$ & $\begin{array}{l}\text { Sampling no. for nationwide } \\
\text { estimate (\%) }\end{array}$ & $\begin{array}{l}\text { Sampling no. for regional } \\
\text { estimates (\%) }\end{array}$ \\
\hline Total & & 7201 & $4165(57.8)$ & $5210(72.4)$ \\
1 & -19 & 2273 & $282(12.4)$ & $282(12.4)$ \\
2 & $20-49$ & 397 & $162(40.8)$ & $397(100)$ \\
3 & $50-99$ & 1219 & $825(67.7)$ & $1219(100)$ \\
4 & $100-149$ & 825 & $548(66.4)$ & $825(100)$ \\
5 & $150-199$ & 773 & $634(82.0)$ & $773(100)$ \\
6 & $200-299$ & 577 & $577(100)$ & $577(100)$ \\
7 & $300-399$ & 492 & $492(100)$ & $492(100)$ \\
8 & $400-499$ & 237 & $237(100)$ & $237(100)$ \\
9 & $500-599$ & 157 & $157(100)$ & $105(100)$ \\
10 & $600-699$ & 105 & $105(100)$ & $54(100)$ \\
11 & $700-799$ & 54 & $54(100)$ & $30(100)$ \\
12 & $800-899$ & 30 & $30(100)$ & $62(100)$ \\
13 & $900+$ & 62 & $62(100)$ & \\
\hline
\end{tabular}

response rate of $60.8 \%$ (Table 2 ). The response rates by region were $64.4 \%$ in Hokkaido, $63.5 \%$ in Tohoku, $55.3 \%$ in Kanto I, $57.1 \%$ in Kanto II, $73.4 \%$ in Hokuriku, $58.7 \%$ in Tokai, $54.4 \%$ in Kinki I, $67.4 \%$ in Kinki II, $63.9 \%$ in Chugoku and Shikoku, $65.9 \%$ in Kitakyushu, and $66.3 \%$ in Minamikyushu.

\section{Nationwide estimate}

The estimated numbers of new hip fracture patients in 2012 were 175,700 in total (95\% CI 170,300-181,100), 37,600 $(36,600-38,600)$ for men and 138,100 (134,300-141,900) for women. As shown in Table 3, the number of new patients in the 2012 survey was 1.2 times larger than that in the 2007 survey [10], and the number of new patients in the 2012 survey was 3.3 times larger than that in the 1987 survey [6]. The number of new female patients increased from 39,700 in 1987 to 138,100 in 2012 .

The annual incidence rate (per 10,000) of hip fracture in 2012 was calculated by sex and age (Table 4). The incidence rates of hip fracture in men and women by age were 0.29 and 0.14 under 40 years, 1.09 and 0.73 in $40 \mathrm{~s}, 2.23$ and 3.13 in $50 \mathrm{~s}, 5.03$ and 8.66 in $60 \mathrm{~s}, 16.88$ and 36.71 in $70 \mathrm{~s}, 60.81$ and 151.03 in $80 \mathrm{~s}$, and 159.46 and 323.25 over 90 years, respectively. The incidence rates in both men and women aged 70-79 years were lowest in

Table 2 Number of responding institutions and response rates for a nationwide estimate and regional estimates by stratum

\begin{tabular}{|c|c|c|c|c|c|c|c|}
\hline Stratum no. & No. of beds & $\begin{array}{l}\text { Sampling no. for } \\
\text { nationwide estimate }\end{array}$ & $\begin{array}{l}\text { No. of responding } \\
\text { institutions }\end{array}$ & $\begin{array}{l}\text { Response } \\
\text { rate }(\%)\end{array}$ & $\begin{array}{l}\text { Sampling no. for } \\
\text { regional estimates }\end{array}$ & $\begin{array}{l}\text { No. of responding } \\
\text { institutions }\end{array}$ & $\begin{array}{l}\text { Response } \\
\text { rate }(\%)\end{array}$ \\
\hline Total & & 4165 & 2615 & 62.8 & 5210 & 3170 & 60.8 \\
\hline 1 & -19 & 282 & 201 & 71.3 & 282 & 201 & 71.3 \\
\hline 2 & $20-49$ & 162 & 91 & 56.2 & 397 & 228 & 57.4 \\
\hline 3 & $50-99$ & 825 & 484 & 58.7 & 1219 & 685 & 56.2 \\
\hline 4 & $100-149$ & 548 & 335 & 61.1 & 825 & 475 & 57.6 \\
\hline 5 & $150-199$ & 634 & 416 & 65.6 & 773 & 493 & 63.8 \\
\hline 6 & 200-299 & 577 & 348 & 60.3 & 577 & 348 & 60.3 \\
\hline 7 & $300-399$ & 492 & 318 & 64.6 & 492 & 318 & 64.6 \\
\hline 8 & $400-499$ & 237 & 156 & 65.8 & 237 & 156 & 65.8 \\
\hline 9 & $500-599$ & 157 & 93 & 59.2 & 157 & 93 & 59.2 \\
\hline 10 & $600-699$ & 105 & 73 & 69.5 & 105 & 73 & 69.5 \\
\hline 11 & 700-799 & 54 & 37 & 68.5 & 54 & 37 & 68.5 \\
\hline 12 & $800-899$ & 30 & 19 & 63.3 & 30 & 19 & 63.3 \\
\hline 13 & $900+$ & 62 & 44 & 71.0 & 62 & 44 & 71.0 \\
\hline
\end{tabular}


Table 3 Trends in estimated number of new hip fracture patients per year, 1987-2012

\begin{tabular}{|c|c|c|c|c|c|c|}
\hline & 1987 & 1992 & 1997 & 2002 & 2007 & 2012 \\
\hline Total point estimation & 53,200 people & 76,600 & 92,400 & 117,900 & 148,100 & 175,700 \\
\hline (95\% confidence interval) & & $69,000-84,000$ & $89,900-94,900$ & $114,700-121,100$ & $144,000-152,200$ & $170,300-181,100$ \\
\hline 5 -yr increase (\% rate of increase) & & $23,400(+44.0 \%)$ & $15,800(+20.6 \%)$ & $25,500(+27.6 \%)$ & $30,200(+25.6 \%)$ & $27,600(+18.6 \%)$ \\
\hline Men point estimation & 13,500 & 18,700 & 20,800 & 25,300 & 31,300 & 37,600 \\
\hline (95\% confidence interval) & & $17,000-21,000$ & $20,100-21,400$ & $24,500-26,000$ & $30,500-32,100$ & $36,600-38,600$ \\
\hline 5 -yr increase ( $\%$ rate of increase) & & $5200(+38.5 \%)$ & $2100(+11.2 \%)$ & $4500(+21.6 \%)$ & $6000(+23.7 \%)$ & $6300(+20.1 \%)$ \\
\hline Women point estimation & 39,700 & 57,900 & 71,600 & 92,600 & 116,800 & 138,100 \\
\hline (95\% confidence interval) & & $52,000-64,000$ & $69,600-73,600$ & $90,000-95,200$ & $113,900-119,700$ & $134,300-141,900$ \\
\hline 5 -yr increase ( $\%$ rate of increase) & & $18,200(+45.8 \%)$ & $13,700(+23.7 \%)$ & $21,000(+29.3 \%)$ & $24,200(+26.1 \%)$ & $21,300(+18.2 \%)$ \\
\hline
\end{tabular}

the 20-year period from 1992 to 2012. Figure 1 shows the ratio of change in incidence rate of hip fracture per 10 , 000, 1992-2012. The incidence rates in both men and women aged 60-79 years tended to decline.

\section{Regional estimates}

Figure 2 shows the east-west regional differences expressed by standardized incidence ratios. Crude incidences of hip fracture per 10,000 by region were high in men in the western areas of Japan (Chugoku 8.28 per 10, 000, Shikoku 8.17 per 10,000, and Kinki II 7.63 per 10, 000 ) compared with those in the eastern areas (Kanto I 4.83 per 10,000, Tokai 5.49 per 10,000, and Tohoku 5.81 per 10,000). The pattern in women was similar, with the

Table 4 Incidence rate of hip fracture per 10,000, 1992-2012

\begin{tabular}{|c|c|c|c|c|c|}
\hline & 1992 & 1997 & 2002 & 2007 & 2012 \\
\hline \multicolumn{6}{|l|}{ Male, age } \\
\hline-39 & 0.36 & 0.30 & 0.30 & 0.32 & 0.29 \\
\hline $40-$ & 1.03 & 0.91 & 0.84 & 0.92 & 1.09 \\
\hline $50-$ & 2.21 & 2.00 & 1.82 & 2.03 & 2.23 \\
\hline $60-$ & 5.74 & 5.12 & 5.26 & 4.81 & 5.03 \\
\hline $70-$ & 19.13 & 17.29 & 17.49 & 18.12 & 16.88 \\
\hline $80-$ & 56.02 & 57.41 & 58.61 & 61.03 & 60.81 \\
\hline $90-$ & 124.96 & 128.89 & 141.39 & 146.62 & 159.46 \\
\hline All ages & 3.08 & 3.38 & 4.08 & 5.11 & 6.10 \\
\hline \multicolumn{6}{|l|}{ Female, age } \\
\hline-39 & 0.16 & 0.13 & 0.12 & 0.15 & 0.14 \\
\hline $40-$ & 0.61 & 0.60 & 0.58 & 0.70 & 0.73 \\
\hline $50-$ & 2.82 & 2.39 & 2.41 & 2.95 & 3.13 \\
\hline $60-$ & 9.69 & 9.07 & 9.11 & 8.11 & 8.66 \\
\hline $70-$ & 44.32 & 40.85 & 41.07 & 39.71 & 36.71 \\
\hline $80-$ & 139.60 & 147.79 & 156.10 & 157.14 & 151.03 \\
\hline $90-$ & 264.66 & 281.04 & 315.52 & 313.58 & 323.25 \\
\hline All ages & 9.20 & 11.19 & 14.43 & 18.14 & 21.31 \\
\hline
\end{tabular}

highest rates in the western areas of Chugoku (29.75 per 10,000), Kinki II (27.30 per 10,000), and Shikoku (26.95 per 10,000) and lower rates in the eastern areas of Kanto I (16.66 per 10,000$)$, Tohoku (18.93 per 10,000$)$, and Tokai (20.01 per 10,000).

Similarity in the patterns for both men and women is noteworthy. Areas in which the incidence ratio was more than $20 \%$ higher in the incidence ratio were Kinki I for men and Kinki I and II for women. Areas in which the incidence ratios were from $10 \%$ to less than $20 \%$ were Kinki II and Chugoku for men and Chugoku and Kitakyushu for women.

\section{Discussion}

The results of our study showed the incidence of hip fracture in 2012 and the trend in hip fracture over a 25-year period. The results showed a drastic increase in the number of patients, especially women. According to data obtained every 5 years, the number of new hip fracture patients has continued to increase. The total number of hip fracture patients was 53,200 in 1987 , and the number increased markedly to 175,700 in 2012 . The number of female hip fracture patients was about 3.7 times larger than the number of male hip fracture patients in 2012, indicating a disparity in sex. It is clear that the number of new patients increases yearly because of changes in the national demographic structure. Between 1985 and 2013, the proportion of people 65 years of age or over in Japan increased from $10.3 \%$ (12.5 million) to $25.1 \%$ (31.9 million; 8.6 to $22.1 \%$ in men and 12.0 to $27.8 \%$ in women). The number of people 65 years of age or over is estimated to increase to 36.6 million in 2025, accounting for more than $30 \%$ of the population of Japan $[12,13]$. A comparison of the aging rate in Japan in 2010 with the rates in other countries shows a considerable disparity: $20.8 \%$ in Germany, $20.3 \%$ in Italy, $18.2 \%$ in Sweden, $16.8 \%$ in France, $13.1 \%$ in the USA, $11.1 \%$ in Korea, $8.4 \%$ in China, and $5.1 \%$ in India. The high rate in Japan in $2010(23.0 \%)$ is an unprecedented situation [14]. 
Fig. 1 Ratio of change in incidence rate of hip fracture per 10,000, 1992-2012

Ratio of change in incidence rate of hip fracture per 10,000,1992-2012

Male

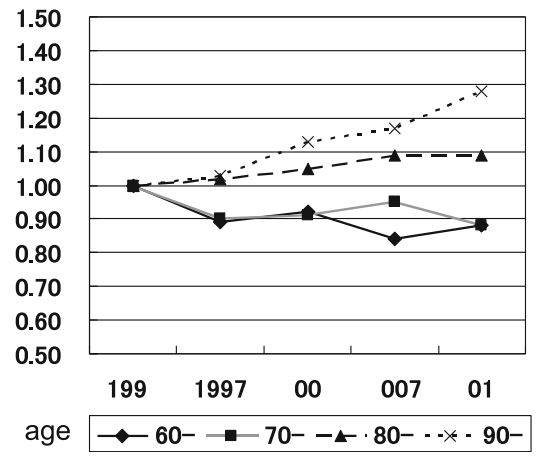

Female

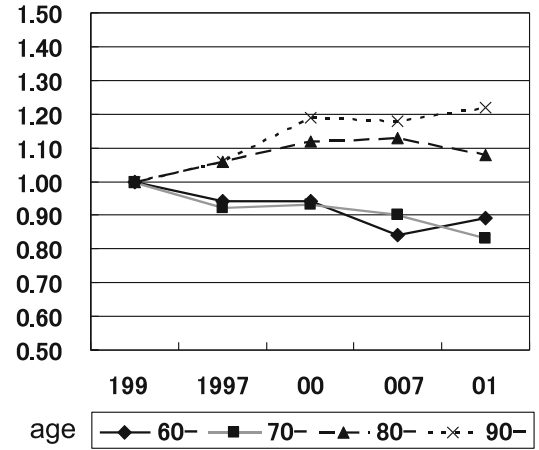

The results of the present study showed that the incidence of hip fracture was higher in western areas than in eastern areas of Japan for both men and women. This trend has not changed since 1987, when the first nationwide survey was carried out. However, the regional difference in incidence of hip fracture seems to be becoming smaller. According to a study on associations between hip fracture incidence and intake of four nutrients, intake of vitamin K showed a possibility of contributing to the regional difference more than did intake of calcium, magnesium, or vitamin D; a high intake of vitamin $\mathrm{K}$ was associated with low incidence of hip fracture, and vice versa [15]. The ranges of intake of vitamin K over an 11-year period from 2002 to 2012 have been decreasing in different areas in Japan; in 2002, 310-320 $\mu \mathrm{g}$ /day in Tohoku and Kanto areas and 230-255 in Shikoku and Kyushu; in 2012, 238-
$261 \mu \mathrm{g} /$ day in Tohoku and Kanto areas and 206-222 in Shikoku and Kyushu. The regional differences in the ranges of vitamin $\mathrm{K}$ intake were 90 in 2002 and 55 in 2012 [16, 17]. Although the levels of vitamin $\mathrm{K}$ intake in the areas were different over the past decade, the range of difference is clearly decreasing. Therefore, the change of regional differences might be partly due to decreases in the differences in intake levels of nutrients by area.

In light of intake of nutrients for bone health, we should reassess our daily lives as well as relying on medicinal benefits such as a variety of bisphosphonates. According to the National Health and Nutrition Survey of Japan, intake of calcium was substantially below the recommended amount in each age group. In 2014, mean values of calcium intake were about $520 \mathrm{mg} /$ day for men and $489 \mathrm{mg}$ /day for women,
Fig. 2 Standardized incidence ratio of hip fracture

\section{Standardized incidence ratio of hip fracture}
1. Hokkaido
2. Tohoku
3. Kanto I
4. Kanto II
5. Hokuriku
6. Tokai
7. Kinki I
8. Kinki II
9. Chugoku
10. Shikoku
11. Kitakyushu
12. Minamikyushu

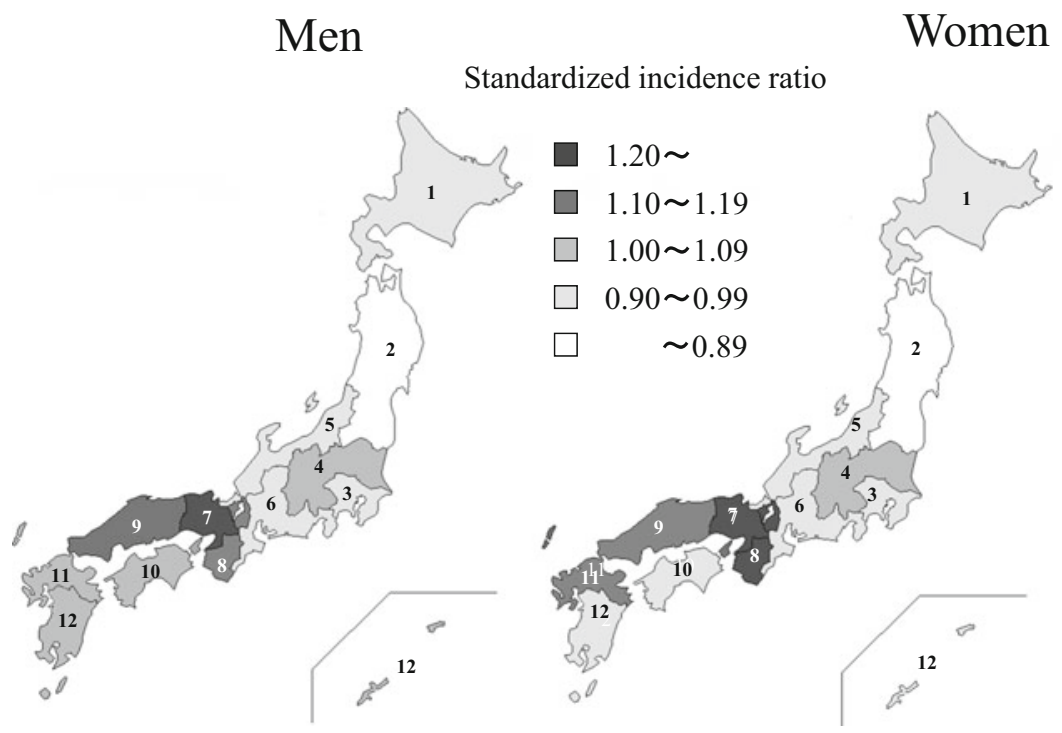


though the recommended values are $650-800 \mathrm{mg} / \mathrm{day}$ for men and $650 \mathrm{mg} /$ day for women [18]. Attention should be given to not only the effects of drugs but also the role of nutritional factors such as calcium, vitamin $\mathrm{K}$, and vitamin $\mathrm{D}$ in bone health.

A study of hip fracture incidence and probability of fracture worldwide showed a greater than 10 -fold variation in hip fracture risk and fracture probability between countries, based on the results of a total of 72 studies from 63 countries. In three categories of age-standardized annual incidence in women, Denmark, Sweden, Austria, and Norway were in the high group, Finland, France, Canada, and Japan were in the moderate group, and Brazil, China, South Arica, and Nigeria were in the low group [19]. According to the first study in which a direct comparison was made of incidence rates of hip/femur fractures in the period 2003-2009 in five European countries including Denmark, the Netherlands, Germany, Spain, and the UK, incidence rates in people over 50 years of age were two to three times higher in Denmark than in other countries. However, only Denmark showed a consistent decline in both males and females aged 70 years or older [20]. A study in Germany, based on data from the national hospital discharge register in 1995-2010, showed that the incidence of hip fracture in women aged 60 years or older decreased or remained constant. The decline in the incidence of hip fracture in women was suggested to be due to programs for prevention of falls and fractures in the elderly, particularly in elderly women in long-term care facilities [21]. A study in Spain, based on data from national hospital discharges nationwide, in which two 4year periods (1997-2000 and 2007-2010) were compared, showed a decrease in age-adjusted rates in the second period (2007-2010) in women, even though the crude incidence increased. Possible causes for the change are intrinsic factors, changes in lifestyle, and also the use of drug therapy and the implementation of strategies to prevent falls and osteoporotic fractures [22]. A study in Italy, in which there is progressive aging of the population as in Japan, based on data from national hospitalization records in 2000-2009 showed that a decreasing trend had started in women aged 65-74 years. The reduction in women aged 65-74 years might already be an effect of the awareness about the treatment of osteoporosis since the beginning of the millennium [23]. A study conducted from 1970 to 2010 in Finland showed that the number of hip fractures rose sharply until the end of the 1990s and also the age-adjusted incidence of hip fracture increased until 1997. However, the incidence declined after 1997, especially in women, and the declining trend has continued through the first decade of this century. Possible reasons for the decline include increased average body weight, improved functional ability among elderly people, and specific measures to reduce the risk of falling [24]. A study in the USA, based on data from national hospital discharge surveys in 1990-2006, showed that age-adjusted hip fracture rates for both men and women declined significantly from 1990 to 2006. The reasons for this trend were suggested to be BMD screening and osteoporosis treatment, cohort effect of a healthier aging population, improved nutrition, and decreased use of psychoactive drugs to decrease fall risk, although there are still unknown protective factors [25]. A recent study in the USA, based on the same data in 1990-2010, suggested that the expected increase in the total number of hip fractures will be largely offset by decreasing hip fracture rates among women, although the number of elderly people in the USA will increase appreciably over the next 20 years. It also stated in that report that there is a need for preventive measures against hip fractures in men [26].

In European countries, the USA and Canada, a fracture liaison service (FLS) has been used to prevent subsequent fractures. An FLS is a multidisciplinary system approach to reducing subsequent fracture risk in patients with a recent fragility fracture by identifying them at or proximate to the time they are treated at the hospital for fracture and providing them with easy access to osteoporosis care. The establishment of an FLS to identify and treat patients with a recent fragility fracture has been shown to be effective, to save money, to be useful for documenting high quality of care, and to make good clinical sense [27].

In an observational study about invitation to an FLS in the Netherlands, it was shown that about half of the patients responded but that half of them did not respond because of lack of interest or being physically unable to attend the clinic. As a result, after 12 months of follow-up, $88 \%$ of the patients persisted with anti-osteoporosis therapy and only $2 \%$ suffered a subsequent clinical fracture. In elderly fracture patients, the use of an FLS leads to an increased response rate, a high rate of persistence in drug treatment, and a low rate of subsequent clinical fractures. For patients that do no respond to an FLS, additional approaches are required [28]. In another study in the Netherlands, patients who visited an FLS had a significantly lower mortality rate and subsequently a lower risk of non-vertebral fracture than did patients who did not visit an FLS. The results showed that an FLS might be a successful approach to reduce the number of subsequent fractures and premature mortality [29]. Moreover, a study in the USA in which the cost-effectiveness of an FLS compared with that of usual care was examined showed and found that under base case assumptions, the FLS reduced fractures, increased quality-adjusted life years, and reduced costs [30].

In 2012, the Japan Osteoporosis Society established an osteoporosis liaison service (OLS) and held several workshops. The main purposes of the OLS are to encourage patients at high risk for fractures to receive osteoporosis treatment and to increase the persistence rate of osteoporosis treatment in order to decrease the fracture risk and incidence rate of hip fracture. A certified osteoporosis manager works as a coordinator in a community, clinics, or hospitals, and the OLS medical staff are actively involved in osteoporosis treatment 
and encourage patients to continue the treatment. There will be more than 600 certified managers in Japan in the near future, and this approach might contribute to a decrease of hip fractures in Japan. In addition to the OLS, instructors for fall prevention and coordinators for locomotive syndrome, which according to the Japanese Orthopedic Association is a high-risk status due to reduced functioning of locomotor apparatuses, work together for both primary and secondary prevention of osteoporosis and hip fracture.

In Japan, first bisphosphonate has been used since 1996, and then a second-generation bisphosphonate, alendronate daily was launched in 2001 and a third-generation bisphosphonate, risedronate daily in 2002 . Their weekly formulations were approved in 2007 and 2008, respectively, and became the first-line medications as in European countries, North America and Oceania. In our previous study on hip fracture incidence in 2007 and the trend for 20 years, we showed that the incidences of hip fractures in 2007 were lowest in men aged 60-69 years and in women aged 60-79 years in a 15year period from 1992 to 2007. A possible reason for this is, we considered, that persons $60-70$ years old with osteoporosis might have come to medical attention and been treated aggressively [10]. In the present study, we found that the incidence rates in both men and women aged 70-79 years were the lowest in the 20-year period from 1992 to 2012. The use of a wide variety of drugs, especially bisphosphonates, for osteoporosis treatment and prevention of hip fracture might have caused the decrease.

Frequencies of administration of these bisphosphonates are drastically changing to monthly or weekly administration from daily administration. In Japan, monthly oral formulation for minodronate was launched in 2011 and risedronate in 2013. A recent study showed a strong patient preference for and convenience of a monthly bisphosphonate regimen over a weekly bisphosphonate regimen among Japanese patients with osteoporosis [31]. Visiting hospitals or clinics to receive an intravenous injection or drip of a bisphosphonate monthly may improve treatment adherence. Recently, monthly injection and drip formulation became available in Japan and they might enable treatment of osteoporosis for patients who have difficulty in taking medicine orally because of other diseases.

Bisphosphonates have been used in many developed countries as first-line therapy for treatment of most patients with osteoporosis. While the use of bisphosphonates has resulted in a significant decrease in morbidity, risks such as osteonecrosis of the jaw and atypical femur fractures and also drug holidays have to be considered [32]. Two recent reports in Norway showed a decreasing hip fracture incidence in Oslo in 2007 and the incidence for the years 2008 to 2010 compared with that for the years 1998 to 2003 in southeastern Norway [33, 34]. The study conducted in Oslo which has the highest hip fracture rate in the world showed a significant decrease in ageadjusted incidence rates for women in 2007 and it was suggested that bisphosphonate use might be part of the reason for the decline. It was estimated that the use of bisphosphonates may explain up to $13 \%$ of the decline in incidence in women aged 60-69 years and up to $34 \%$ in women aged 70-79 years [33]. The other study in southeastern Norway showed that the incidence of hip fracture in the years 2008 to 2010 was similar to that in the years 1998 to 2003. The rate of bisphosphonate use did not exceed $2 \%$ in any of the groups for men, and the highest rate was $12.6 \%$ in the group of women aged 85-89 years. Although bisphosphonate drugs have been prevalent since the late 1990s, it is difficult to determine their effectiveness [34]. A study in Australia suggested that the decline in hip fracture rates was largely due to the use of bisphosphonates, although there was no clear understanding of factors related to change in the epidemiology of the incidence of hip fracture. A decline in the use of bisphosphonates was shown to be associated with an increase in hip fracture rates in females, indicating that bisphosphonates should still be considered as first-line medications for the prevention and treatment of osteoporosis [35]. Another study in Spain showed that a substantial increase in bisphosphonate use from 2002 to 2008 was weakly but significantly correlated with a drop (2.2\%) in standardized hip fracture rates in women. It was also stated that factors including lifestyle advice, health campaigns, self-awareness, improvement in residence conditions, and dietetic changes could partially explain the decline in hip fracture rates [36].

Our study has several limitations. First, we used the mail-in method because we do not have a nationwide computer-based register system of hip fractures. At present, this is the best way to obtain information on hip fractures as a nationwide survey. In order to receive as many responses as possible, we asked for responses three times. Moreover, we dealt with questions from institutions by telephone. Second, although we asked institutions not to include patients that underwent surgery for hip fracture at other institutions or patients for rehabilitation, it was not possible to check them. Third, since we collected data for all hip fracture patients together, it was not possible to distinguish between fractures caused by primary osteoporosis and those caused by secondary osteoporosis. It was also impossible to analyze data by types of hip fracture.

In conclusion, despite the increasing number of new patients, the incidence of hip fracture in both men and women aged 70-79 years showed the possibility of decline. The exact reasons for this are unknown, but various kinds of drugs for improving bone mineral density or preventing hip fracture might have contributed to the results. A decrease in the differences of nutrient intake levels might explain some of the change in regional differences in Japan. Comprehensive countermeasures including drug therapy, cooperation among the OLS medical staff, instructors for fall prevention and coordinators for locomotive syndrome, and adequate nutritional intake will be key factors for hip fracture prevention. 
Acknowledgments This study was supported by Japan Osteoporosis Foundation and Japan Osteoporosis Society. We wish to express our sincere thanks to all hospitals and clinics which participated in this survey, and also to Mr. Tomoyuki Nakayama.

\section{Compliance with ethical standards}

Conflicts of interest None.

\section{References}

1. Rachner TD, Khosla S, Hofbauer LC (2011) Osteoporosis: now and the future. Lancet 377:1276-1287

2. Cummings S, Melton L (2002) Epidemiology and outcomes of osteoporotic fractures. Lancet 359:1761-1767

3. Shi N, Foley K, Lenhart G, Badamgarav E (2009) Direct healthcare costs of hip, vertebral, and non-hip, non-vertebral fractures. Bone 45:1084-1090

4. Ministry of Health, Labour and Welfare, Japan (2010) Comprehensive survey of living conditions (in Japanese)

5. Cabbinet Office, Government of Japan (2014) White paper on aging society

6. Orimo H, Hosoda Y, Fujiwara S, Mizuno S, Hashimoto T, Tamaki T, Nose T, Yamamoto K, Sasaki R (1991) Hip fracture incidence in Japan. J Bone Miner Metab 9:89-93

7. Orimo H, Hashimoto T, Yoshimura N, Fujiwara S, Hosoi T, Shiraki M, Fukunaga M, Nakamura T, Fukushima Y (1997) Nationwide incidence survey of femoral neck fracture in Japan, 1992. J Bone Miner Metab 15:89-93

8. Orimo H, Hashimoto T, Sakata K, Yoshimura N, Suzuki T, Hosoi T (2000) Trends in the incidence of hip fracture in Japan, 1987-1997: the third nationwide survey. J Bone Miner Metab 18:126-131

9. Orimo H, Sakata K (2004) Hip fracture incidence in Japan in 2002: report of the 4th nationwide survey for hip fracture. Nihon Iji Shinpo (Jpn Med J) 25-30

10. Orimo H, Yaegashi Y, Onoda T, Fukushima Y, Hosoi T, Sakata K (2009) Hip fracture incidence in Japan: estimates of new patients in 2007 and 20-year trends. Arch Osteoporos 4:71-77

11. Groves R, Fowler F, Couper M, Lepkowski J, Singer E, Tourangeau R (2009) Survey methodology, 2nd edn. Wiley, New Jersey

12. Ministry of Internal Affairs and Communications, Japan (2013) Population Estimates

13. National Institute of Population and Social Security Research (2012) Projection: Population and Household

14. World Population Prospects (2012) Department of Economics and Social Affairs, United Nations

15. Yaegashi Y, Onoda T, Tanno K, Kuribayashi T, Sakata K, Orimo $H$ (2008) Association of hip fracture incidence and intake of calcium, magnesium, vitamin $\mathrm{D}$, and vitamin $\mathrm{K}$. Eur J Epidemiol 23:219-225

16. Ministry of Health, Labour and Welfare, Japan (2002) The National Health and Nutritional Survey

17. Ministry of Health, Labour and Welfare, Japan (2012) The National Health and Nutritional Survey

18. Ministry of Health, Labour and Welfare, Japan (2014) The National Health and Nutritional Survey

19. Kanis JA, Oden A, McCloskey EV, Johansson H, Wahl DA, Cooper C (2012) A systematic review of hip fracture incidence and probability of fracture worldwide. Osteoporos Int 23:2239-2256

20. Requena G, Abbing-Karahagopian V, Huerta C et al (2014) Incidence rates and trends of hip/femur fractures in five European countries: comparison using e-healthcare records databases. Calcif Tissue Int 94:580-589

21. Icks A, Arend W, Becker C, Rapp K, Jungbluth P, Haastert B (2013) Incidence of hip fractures in Germany, 1995-2010. Arch Osteoporos 8:140

22. Azagra R, Lopez-Exposito F, Martin-Sanchez JC, Aguye A, Moreno N, Cooper C, Diez-Perez A, Dennison EM (2014) Changing trends in the epidemiology of hip fracture in Spain. Osteoporos Int 25:1267-1274

23. Piscitelli P, Feola M, Rao C et al (2014) Ten years of hip fractures in Italy: for the first time a decreasing trend in elderly women. World $\mathrm{J}$ Orthop 5:386-391

24. Korhonen N, Niemi S, Parkkari J, Sievanen H, Palvanen M, Kannus P (2013) Continuous decline in incidence of hip fracture: nationwide statistics from Finland between 1970 and 2010. Osteoporos Int 24:1599-1603

25. Stevens JA, Rudd RA (2010) Declining hip fracture rates in the United States. Age Ageing 39:500-503

26. Stevens JA, Rudd RA (2013) The impact of decreasing U.S. hip fracture rates on future hip fracture estimates. Osteoporos Int 24: $2725-2728$

27. Curtis JR, Silverman SL (2013) Commentary: the five Ws of a Fracture Liaison Service: why, who, what, where, and how? In osteoporosis, we reap what we sow. Curr Osteoporos Rep 11: 365-368

28. Eekman DA, van Helden SH, Huisman AM, Verhaar HJJ, Bultink IEM, Geusens PP, Lips P, Lems WF (2014) Optimizing fracture prevention: the fracture liaison service, an observational study. Osteoporos Int 25:701-709

29. Huntjens KM, van Geel TA, van den Bergh JP et al (2014) Fracture liaison service: impact on subsequent nonvertebral fracture incidence and mortality. The Journal of bone and joint surgery American volume 96:e29

30. Solomon DH, Patrick AR, Schousboe J, Losina E (2014) The potential economic benefits of improved postfracture care: a costeffectiveness analysis of a fracture liaison service in the US health-care system. J Bone Miner Res 29:1667-1674

31. Iwamoto J, Okano H, Furuya T, Urano T, Hasegawa M, Hirabayashi H, Kumakubo T, Makita K (2015) Patient preference for monthly bisphosphonate versus weekly bisphosphonate in a cluster-randomized, open-label, crossover trial: Minodroate Alendronate/Risedronate Trial in Osteoporosis (MARTO). J Bone Miner Metab. doi:10.1007/s00774-015-0653-7

32. McClung M, Harris ST, Miller PD et al (2012) Bisphosphonate therapy for osteoporosis: benefits, risks, and drug holiday. Am J Med 126:13-20

33. Stoen RO, Nordsletten L, Meyer HE, Frihagen JF, Falch JA, Lofthus CM (2012) Hip fracture incidence is decreasing in the high incidence area of Oslo, Norway. Osteoporos Int 23:2527-2534

34. Polesie S, Sigurdsen U, Bjorgul K (2013) Unchanging incidence of hip fracture in Southeastern Norway. Geriatr Orthop Surg Rehabil 4:58-63

35. Fisher A, Martin J, Srikusalanukul W, Davis M (2010) Bisphosphonate use and hip fracture epidemiology: ecologic proof from the contrary. Clin Interv Aging 5:355-362

36. Arias LH, Treceno C, Garcia-Ortega P, Rodriguez-Paredes J, Escudero A, Sainz M, Salado I, Velasco V, Carvajal A (2013) Hip fracture rates and bisphosphonate consumption in Spain. An ecologic study. European J Clin Pharmacol 69:559-564 